\title{
LIBERDADE NO CONTEXTO DA PANDEMIA DO NOVO CORONAVÍRUS
}

\author{
FREEDOM IN THE CONTEXT OF THE NEW CORONAVIRUS PANDEMIC
}

Everton Limberger

Leandro da Maia $^{2}$

Cleina Roberta Biagi ${ }^{3}$

Acadêmico da $4^{a}$ série de Psicologia da Universidade Paranaense - UNIPAR Campus Cascavel/PR. Bacharel em Filosofia (2006) pela Universidade Estadual Do Oeste Do Paraná UNIOESTE Campus Toledo/PR. Endereço para correspondência: Rua Manaus, $\mathrm{n}^{\circ}$ 2859, Bairro Cancelli - CEP 85811-030, Cascavel/PR.

E-mail:vrtn76@gmail.com.

2 Acadêmico da $4^{\text {a }}$ série de Psicologia da Universidade Paranaense - UNIPAR Campus Cascavel/PR. Endereço para correspondência: Rua Presidente Juscelino Kubitschek, $\mathrm{n}^{\circ} 1837$, apto 01, Bairro Recanto Tropical - CEP 85807-435, Cascavel/PR.

E-mail: leandro.maia@edu.unipar.br.

${ }^{3}$ Docente/Orientadora do curso de Psicologia da Universidade Paranaense - UNIPAR Campus Cascavel/PR. Endereço para correspondência: R. Rui Barbosa, 611 - Jardim Cristal, CEP: 85810-240. Cascavel - PR.

E-mail: cleina@prof.unipar.br.
LIMBERGER, E.; MAIA, L. de; BIAGI, C. R.; Liberdade no contexto da pandemia do novo coronavírus. Akrópolis, Umuarama, v. 29, n. 1, p. 75-84, jan./jun. 2021.

\section{DOI: https://doi.org/10.25110/akropolis.v29i1.8328}

Resumo: A pandemia de coronavírus provocou diversas mudanças de hábitos, costumes, lazer e saúde, causando discordâncias de opiniões e sofrimentos psíquicos entre a população. O presente artigo, tem por finalidade, abordar a partir de uma visão fenomenológica existencial, a liberdade vivida durante a situação da pandemia. Buscando promover uma reflexão a partir dos conceitos fenomenológicos existenciais, como responsabilidade, facticidade, projeto original, entre outros. Relacionando esses com as orientações e protocolos sugeridos durante o período pandêmico. Diante da importância deste tema, atualmente, e na procura de empoderar a ciência, pretende-se compreender como a liberdade têm ocorrido neste período e quais questões a permeiam. Além disso, as escolhas tornaram-se cada vez mais fundamentais para a existência, impactando diretamente na vida de todos e indicando a nossa responsabilidade para com toda a humanidade, ainda mais em um momento em que muitas pessoas correm risco em virtude de um novo vírus.

Palavras-chave: Existencialismo; Pandemia; Liberdade.

ABSTRACT: The coronavirus pandemic has caused several changes in habits, behavior, leisure, and health, and has provoked many divergent opinions and psychological suffering among the population. This article aims at approaching, from an existential phenomenological view, the experience of freedom during the COVID-19 pandemic. It seeks to promote a reflection from the existential phenomenological concepts (e.g. responsibility, facticity, original project, etc.). It correlates the former with the guidelines and protocols that have been suggested during the pandemic period. Given the current importance of this theme and in the pursuit to empower science, this study intends to understand how freedom has occurred during the pandemic and what questions permeate it. In addition, choices have become increasingly fundamental for existence, impacting everyone's lives and indicating our responsibility towards the entire humanity, especially during a period where many people are at risk due of the new coronavirus.

KeYwords: Existentialism; Pandemic; Freedom. 


\section{INTRODUÇÃO}

O ano de 2020 ficará marcado em decorrência do surgimento de uma pandemia, o novo coronavírus, como foi denominado, provocou muitas mudanças no modo de vida da população mundial. Hábitos, costumes, trabalho, lazer e principalmente a saúde foram profundamente afetados. Tornou-se necessário adotar medidas de distanciamento, isolamento social e uso de itens de proteção individual.

Adotar tais medidas provocou divergências de opinião e de comportamento entre líderes, população e autoridades na área de saúde. Passou-se então a serem divulgados protocolos de segurança sanitária para a população em geral, surgindo assim, uma espécie de divisão entre a mesma. De um lado, as pessoas que imediatamente adotaram tais protocolos, de outro, as que apresentaram certa resistência na adoção das medidas apresentadas, principalmente entre a população brasileira, supostamente, como uma possível consequência da polarização sentida politicamente na atualidade do país.

Além disso, é importante destacar a situação de pessoas que não conseguiram fazer o isolamento, que continuaram trabalhando por necessidade e há também aquelas que não puderam adotar tal medida por questões sociodemográficas, como por exemplo, nas comunidades carentes e em residências ou cidades em que há uma concentração grande de pessoas, como afirma o infectologista Marco Aurélio Sáfadi, diretor do Departamento de Infectologia da Sociedade Brasileira de Pediatria (SBP) e diretor do Departamento de Pediatria da Faculdade de Ciências Médicas da Santa Casa de São Paulo, em entrevista dada ao portal 'Agência Brasil' (COSTA, 2020).

Podemos apontar aqui também, o fato de pessoas que não se enquadraram em nenhum dos planos emergenciais oferecidos pelo governo e que não tiveram outra opção para sobrevivência, a não ser a de continuar trabalhando, uma escolha entre o risco de infectar-se pelo coronavírus e o risco de passar fome, como mostra o epidemiologista e professor da Universidade de São Paulo, Paulo Lotufo em matéria publicada pela 'Agência O Globo' (LEÃO, 2020).

Essas situações, desenvolveram sentimentos variados entre a população, tais como angústia, ansiedade e outros sofrimentos psíquicos. As escolhas, que segundo Sartre compõem a subjetividade de cada indivíduo, foram, nesse momento de pandemia, permeadas por questões como a sobrevivência e a angústia por conviver com o desconhecido (COVID-19) e as incertezas de como seria a vida a partir deste momento.

Diante do exposto, este trabalho tem como objetivo refletir sobre a liberdade de cada indivíduo no contexto desta pandemia, tomando por base o conceito de liberdade descrito por Sartre, além de nossas responsabilidades e escolhas. Relacionando esse conceito de liberdade com as orientações da comunidade médica, científica e de saúde à população, sobre os protocolos de prevenção contra o coronavírus, procurou-se oferecer à comunidade acadêmica e a quem possa interessar, informações relevantes e pertinentes, demonstrando a importância da ciência e de suas pesquisas para produzir bemestar e prestar orientações para a população no enfrentamento de um vírus desconhecido. A partir dessa reflexão sobre a responsabilidade de cada indivíduo diante do escolher-se, de suas ações e de acontecimentos que não podem ser controlados pelo sujeito (facticidade), tendo sempre como guia o pensamento sartreano que afirma que "se considero que determinada ação é boa, sou eu mesmo que escolho afirmar que ela é boa e não má" (SARTRE, 1970, p. 6).

\section{DESENVOLVIMENTO}

Considerando a liberdade e o conceito da má-fé descritos por Sartre, como podemos ser livres em tempos difíceis e diante das escolhas que teremos que fazer em um momento que o mundo experiencia uma pandemia?

Sartre (2018, p. 545) afirma que "o homem não poderia ser ora livre, ora escravo: é inteiramente e sempre livre, ou não o é" e isso acaba influenciando toda e qualquer relação interpessoal, seja em um meio familiar ou em um mundo em que vive uma pandemia. Para compreender melhor a ideia de liberdade em Sartre torna-se importante retomar o que ele diz:

[...] o homem, estando condenado a ser livre, carrega nos ombros o peso do mundo inteiro: é responsável pelo mundo e por si mesmo enquanto maneira de ser. Tomamos a palavra "responsabilidade" em seu sentido corriqueiro de "consciência (de) ser o autor incontestável de um acontecimento ou de 
um objeto" (SARTRE, 2018, p. 678).

No momento em que o mundo experiencia um surto pandêmico, a responsabilidade recai sobre cada atitude ou ação de cada indivíduo, pois as escolhas individuais podem afetar diretamente a vida e a liberdade do outro. Segundo Sartre (1970, p. 5) "Sou, desse modo, responsável por mim mesmo e por todos e crio determinada imagem do homem por mim mesmo escolhido; por outras palavras: escolhendo-me, escolho o homem". Desta forma, proteger-se ou não contra o vírus, é um exemplo do que Sartre nos mostra sobre o quanto a escolha de um indivíduo afeta a vida dos demais.

Em um contexto de pandemia, os órgãos responsáveis de saúde se veem obrigados a olhar por todos os indivíduos de forma singular e universal. De acordo com o pensamento sartreano, o homem é singular e universal e a respeito disso o autor afirma que:

Um homem nunca é um singular individual; seria melhor chamá-lo um singular universal; totalizado e, em virtude disso, universalizado por sua época, ele a retotaliza como uma singularidade. Universal pela universalidade singular da história humana; singular pela singularidade universalizante de seus projetos. Ele requer ser estudado simultaneamente de ambos os lados (SARTRE, 1981, p. 7-8).

Nessas circunstâncias, o olhar dos órgãos responsáveis pela saúde mundial afeta na questão da liberdade, das ações e escolhas possíveis de maneira individual e coletiva. Sobre isto, podemos afirmar que o homem nunca é um indivíduo e sim um ser singular-universal-singular (SARTRE, 1971 apud BOCCA, 2019), ou seja, "os indivíduos refletem as características universais de seu tempo e, inversamente, que os universais de uma época são realizados concretamente e singularmente pelos indivíduos (BARATA, 2018 apud BOCCA, 2019). Dessarte, a essência do homem é construída a partir das relações que estabelece com outras pessoas e com os objetos.

Um exemplo disso é o que nos mostra Bezerra et al. (2020) em seu artigo em que destaca a discussão que vem sendo promovida pela mídia e a população em geral:

Existe uma discussão na mídia e no senso comum de que a parcela com menor renda está praticando menos o isolamento social em relação àquela com maior renda, principalmente em função da necessidade de locomoção para o trabalho, uma vez que a população mais pobre está vinculada a atividades essenciais que não pararam, e a população com maior renda está, de forma geral, mais vinculada às atividades que pararam e/ou estabeleceram o trabalho remoto. Outros fatores que interferem no isolamento social também são questionados pela mídia e pela academia, como, por exemplo, as diferenças nas condições de habitabilidade entre as pessoas de maior e menor renda (BEZERRA et al., 2020, p. 2412).

As escolhas aqui, estão perpassadas por inúmeras questões de ordem econômica, social, cultural, etária, etc., onde o simples fato de ir trabalhar torna-se uma escolha que afeta a escolha de outra pessoa, como por exemplo, o motorista do ônibus, que também vai precisar decidir por ir ou não ao seu emprego, cuidar ou não de sua saúde. Muitas pessoas tiveram condições de fazer isolamento e/ou continuar trabalhando de casa, mas outras não tiveram essa possibilidade devido a várias condições, como a questão financeira ou da área de trabalho que não possibilita a realização da atividade de maneira remota.

Em contrapartida, percebe-se a existência de pessoas que tem a necessidade de sair de suas casas, mesmo durante a medida de isolamento. Os motivos que levam essas pessoas às ruas ou outros espaços vão desde a necessidade de prática de atividades físicas para o bem-estar físico e mental como aquelas pessoas que se encontram em situações de vulnerabilidade social e econômica e que dividem com muitas pessoas uma residência com poucos recursos e até muitas vezes em condições precárias, tornando o isolamento uma condição sub humana, como afirma Bezerra et al.:

[...] as condições de habitação impõem claras limitações ao isolamento social e a adoção das medidas de higiene apontadas pelas organizações sanitárias como essenciais para evitar a contaminação pelo vírus. Portanto, o confinamento domiciliar a partir dessas condições requer medidas complementares por parte dos governos visando garantir padrões mínimos de higiene, salubridade e bem-estar 
(BEZERRA et al., 2020, p. 2418).

Este tipo de situação pode ocasionar imensos sofrimentos para as pessoas, como tristeza, angústia, tédio, estresse, incertezas, medo, entre outros. Como consequência, a ansiedade do retorno ou retomada de uma vida "normal" passa a provocar a perda da qualidade de vida, de um modo geral, afetando desde o sono até as relações sociais.

Nesse momento, cada pessoa precisou buscar formas para lidar com os seus sentimentos e com o seu tempo. Assim, surgiram várias formas de comunicação, de interação social, em sua grande maioria remotas. Segundo Malavé (2020), a internet possibilitou a existência do trabalho home office, a continuação das aulas de forma remota, novas formas de comércio, desfrutar de lazer e cultura, entre outros, que já vinham acontecendo nos últimos anos e foram potencializados durante o isolamento na pandemia. Sendo assim, a Internet tornou-se grande aliada nas interações e uma ferramenta que contribuiu para as pessoas lidarem com a situação, seja no âmbito de entretenimento ou até mesmo formação profissional na educação e no trabalho, além de possibilitar a manutenção do contato com familiares e amigos, entre outros.

\section{NOVO CORONAVÍRUS E OS MÉTODOS PREVENTIVOS}

Para contextualizar a linha de reflexão deste trabalho, é importante retomar algumas orientações das autoridades em saúde, destinadas à população em geral. Tais recomendações têm como o intuito a prevenção contra o novo Coronavírus.

De acordo com a OPAS (Organização PanAmericana de Saúde), que atua como escritório regional da OMS (Organização Mundial da Saúde) no continente americano, no dia 30 de janeiro de 2020 a OMS declarou que o surto da doença causada pelo novo coronavírus, a COVID-19, constituía uma Emergência de Saúde Pública, o alerta de mais alto nível da Organização. Em 11 de março de 2020, o diretor-geral da OMS, Tedros Adhanom Ghebreyesus, anunciou em Genebra na Suíça que a doença era agora considerada uma pandemia. Diante deste panorama, algumas medidas de prevenção deveriam ser adotadas para diminuir a taxa de disseminação do vírus e o risco de contaminação, já que ainda não há uma vacina e medicamentos com eficácia totalmente comprovada para prevenir ou tratar a doença. $\mathrm{Na}$ sequência, apresentamos algumas das principais medidas que deveriam ser adotadas durante este período.

A SAPS (Secretaria de Atenção Primária à Saúde) e o Ministério da Saúde desenvolveram em maio de 2020 um Guia Orientador para o enfrentamento da Pandemia na Rede de Atenção à Saúde e a partir das informações contidas neste, especifica-se algumas das medidas para lidar com o vírus:

- Lavar as mãos frequentemente com água e sabão ou com desinfetante para as mãos à base de álcool $70 \%$;

- Evitar tocar olhos, nariz e boca com as mãos não estando devidamente limpas;

- Evitar contato próximo com as pessoas, mantendo distanciamento de no mínimo 1 metro;

- Cobrir boca e nariz com o antebraço ao tossir ou espirrar com lenços descartáveis, descartando-os imediatamente após o uso em um lixo fechado e higienizando as mãos em seguida;

Outras medidas de prevenção tiveram que ser adotadas à medida que o vírus se propagava, como por exemplo a utilização de máscaras. O Guia Orientador para o enfrentamento da Pandemia na Rede de Atenção à Saúde, do CONASENS - Conselho Nacional de Secretarias Municipais de Saúde; CONASS - Conselho Nacional de Secretários da Saúde (2020) ainda fala sobre a utilização das máscaras. A máscara de pano pode ser um método de barreira fundamental junto aos demais métodos de higiene e a utilização frequente do álcool em gel. $O$ isolamento também foi uma prática adotada, que teve como objetivo separar as pessoas com suspeita ou com um quadro já confirmado das pessoas saudáveis. Além disso, uma das medidas tomadas que causaram um impacto muito grande no modo em que vivemos foi o distanciamento social. O principal objetivo desta medida é reduzir a velocidade de transmissão do vírus, achatando a curva de crescimento do novo coronavírus. A transmissão ainda ocorre, porém de forma menos acelerada, e isso faz com que o sistema de saúde tenha tempo para reforçar sua estrutura com respiradores e demais equipamentos 
e também com médicos, enfermeiros, biomédicos, entre outros profissionais da área da saúde.

\section{PANORAMA GERAL E CRÍTICA}

O desencontro de informações sobre o coronavírus no mundo todo, acabou pordesencadear no Brasil uma politização sobre o assunto. Ressaltase que já existia uma forte tendência de divisão de pensamento político, por parte da população e dos governantes, principalmente por ser um ano eleitoral, corroborando para questionamentos sobre a eficiência e eficácia de tratamentos, medicamentos e dos protocolos adotados como prevenção. Citase como exemplo de desencontro de informação a notícia veiculada pelo portal de notícias brasileiro G1, no dia 08 de junho de 2020, onde Maria Van Kerkhove, chefe da unidade de doenças emergentes da OMS, afirmou que pacientes assintomáticos não estavam impulsionando a disseminação da Covid-19. No dia seguinte, 09 de junho de 2020, o G1 publicou uma matéria onde a OMS esclareceu que os assintomáticos também transmitiam o vírus, só não se sabia qual a proporção. Desencontros como este, vindo da entidade máxima de saúde no mundo, propiciam uma desconfiança na população e é um fator propulsor para os que negam as orientações de saúde e até mesmo a existência do coronavírus.

Outro ponto importante a ser destacado foi como os governantes reagiram diante da pandemia e das medidas de segurança que deveriam ser adotadas para reduzir o contágio. Muitos deles acabaram priorizando a questão econômica de seus respectivos países e tentaram por meio de seus discursos minimizar o impacto na saúde e o real perigo do novo coronavírus. Em virtude desses discursos opostos entre entidades de saúde e governantes, a população ficou à mercê de uma orientação clara de como agir neste período e sobre a real gravidade do vírus.

\section{LIBERDADE E FACTICIDADE}

Um dos equívocos ao entender os filósofos existencialistas, mais especificamente o conceito de liberdade descrita por eles, é entender essa liberdade como absoluta, em que se pode fazer tudo que se queira fazer. Mas a liberdade depende da situação, como afirma Perdigão:
O lugar que ocupamos, o nosso corpo, o passado imutável, a existência dos outros, tudo isso define a nossa situação. Tratase de pura facticidade que nos é imposta, na qual deparamos com obstáculos e resistências que não foram criadas por nós e não podemos evitar (PERDIGÃO, 1995, p. 95).

Dessa forma, a pandemia surge para a humanidade como uma facticidade, algo que está imposto e que não foi criado por nós e não podemos evitar que aconteça, muito menos depende da nossa vontade e da nossa escolha a existência deste obstáculo. Ou seja, a situação em que estamos inseridos neste momento é pura facticidade, confirmando que nossa liberdade é uma liberdade situada. Então, a pandemia e as medidas de prevenção adotadas alteram o modo como a nossa liberdade de escolher se dá e também afetam nossos projetos, nossa rotina e o modo como as relações acontecem e principalmente, o foco passa a ser evitar uma possível contaminação e transmissão do vírus.

A existência da pandemia do novo coronavírus não pode ser vista como um fim para a liberdade, pois ainda possuímos a capacidade de fazer escolhas e devemos arcar com as responsabilidades destas. Sartre afirma que:

O coeficiente de adversidade das coisas, em particular, não pode constituir um argumento contra nossa liberdade, porque é por nós, ou seja, pelo posicionamento prévio de um fim, surge o coeficiente de liberdade. Determinado rochedo, que demonstra profunda resistência se pretendo removê-lo, será, ao contrário, preciosa ajuda se quero escalá-lo para contemplar a paisagem (SARTRE, 2018, p. 593).

Seguindo esse pensamento, percebe-se que cada indivíduo exerce sua liberdade ao dar significado às coisas, mesmo diante da impotência de mudar o passado ou aquilo que já foi de certa forma significado por outros antes mesmo do nascimento desse indivíduo. O que resta então durante este período é lidar com nossa liberdade, mesmo que situada, por meio de nossas escolhas e assumindo responsabilidades. Porém, percebese que há aqueles que agem de má-fé para com a sua liberdade.

Sartre chama de má-fé a forma de 
comportamento que o indivíduo cria para lidar com sua angústia. O objetivo é transformar-se em uma coisa, de forma intencional, livrandose do "peso" da decisão e da liberdade. É uma atitude de negação para si mesmo (ERTHAL, 2013). Correlacionado a esse conceito, notou-se durante a pandemia, diante das orientações de protocolos de cuidados e uso de equipamentos de proteção, a resistência por parte de algumas pessoas em adotar tais medidas de proteção, como o uso de máscaras, o distanciamento social assim como 0 isolamento durante as determinações de lockdown (paralisação total de atividades). Conforme prossegue Erthal (2013, p.118), na máfé, o indivíduo esconde uma verdade que não lhe é agradável aos seus olhos ou apresenta como verdade uma não verdade prazerosa. Percebeu-se então, durante este período, que muitas pessoas acabaram por negar a existência da pandemia e dos seus riscos, pois o impacto repentino em sua vida não soaria agradável, além de ter que tomar cuidados específicos que antes não eram necessários. Ainda segundo a autora:

Muitos indivíduos vivem como se aceitassem passivamente sua existência, atribuindo significados superficiais à sua própria vida. Age-se mecanicamente como para fugir de um enfrentamento com dados reais, o que lhe exigiria uma atitude decisória. Esse comportamento é a própria má-fé. Uma atitude de negação voltada para si mesmo, que por vezes é confundida com a mentira (ERTHAL, 2013, p. 121).

Logo, a atitude de má-fé está sendo percebida durante o período pandêmico, onde muitos indivíduos procuraram fugir do enfrentamento dos dados reais e ignoraram a situação vivenciada em todo mundo.

Um estudo publicado pela revista 'Nature Human Behaviour' em 31 de junho de 2020, mostra que em média, no Brasil, uma pessoa que estava com o vírus infectou três novas pessoas, um número levemente maior que em outros países que estavam enfrentando a pandemia. Dessa forma, as escolhas se mostram importantes para o homem e para toda a humanidade:

Um outro ponto também afirmado pelo existencialismo e expresso por Sartre é que o homem é "condenado" a sua liberdade, isto é, vê-se forçado a fazer escolhas diante mesmo do desconhecimento da sua própria existência. Não dá para não fazer escolhas; mesmo a não escolha já é uma opção escolhida pelo homem (ERTHAL, 2004, p. 58).

Esses dados revelam que as escolhas tomadas durante a pandemia são carregadas de importância e responsabilidade, além do fato de que não é possível não escolher, mesmo escolhendo não escolher, já estamos realizando uma escolha.

Dessa maneira, o impacto de escolher o negacionismo perante a doença e os cuidados a serem tomados afetam toda a humanidade, colocando em risco a saúde das demais pessoas e criando um ambiente propício para a propagação do vírus. Algumas pessoas que acabaram contraindo a doença estavam trabalhando ou desenvolvendo atividades essenciais durante o período, mas também existem pessoas que não seguiram as orientações e acabaram interrompendo a quarentena por escolha e por querer exercer o direito à liberdade, mas de acordo com Perdigão (1995), nossa liberdade é situada, ou seja, ela depende do contexto em que estamos inseridos e a pandemia mostra bem o quanto nossa liberdade não é absoluta.

Segundo Cardoso (2020), um grande exemplo de movimento que foi intensificado durante este período de pandemia, são os grupos antivacina. Esse tipo de grupo age, de má-fé, compartilhando informações falsas, distorcendo conteúdos e até mesmo criando teorias conspiracionistas sobre o efeito do uso das vacinas.

De acordo com a União Pró-Vacina, que é um projeto criado por instituições de pesquisa e acadêmicas da USP na cidade de Ribeirão Preto, movimentos antivacina com grupos na rede social Facebook, criam e compartilham publicações que negam evidências científicas, e até mesmo sugerem o uso de remédios e/ou tratamentos alternativos que não possuem comprovação científica.

Nos últimos anos, a incidência deste tipo de grupo vem crescendo, principalmente com a facilidade de acesso à internet e informações por meio das redes sociais. Com a chegada de uma pandemia, as ações e publicações deste tipo de grupo começaram a crescer e voltaram o seu foco para o novo coronavírus. Ainda de acordo com esse estudo realizado pela União Pró-Vacina, conteúdo das postagens é preocupante, pois: 
[...] $8,4 \%$ apresentam sérios problemas, como a disseminação de teorias da conspiração, utilização de informações falsas e de afirmações sem evidências, a distorção de informações confiáveis, a sugestão de uso e até a comercialização de produtos e tratamentos que não possuem comprovação científica ou aprovação da Agência Nacional de Vigilância Sanitária (Anvisa) (CARDOSO, 2020, s/p).

Sendo assim, os grupos e os membros principais do movimento antivacina agem de máfé, compartilhando e criando informações falsas e não comprovadas cientificamente, influenciam muitas pessoas e impactam negativamente para as campanhas de vacinação e meta a serem atingidas. A responsabilidade deste tipo de grupo acaba engajando muitas pessoas neste movimento, principalmente aquelas que não sabem filtrar ou até mesmo verificar a veracidade das informações que está lendo ou sendo veiculada, gerando ansiedade e causando dúvidas nestas pessoas, que por muitas vezes acabam repassando adiante estas informações sem verificar a autenticidade e confiabilidade das fontes e assim tais grupos vão cada vez mais conquistando espaço nas mídias e novos adeptos, além de cercear a liberdade do outro, pois na disseminação de falsas notícias fazem coro para as pessoas pensarem e escolherem como eles, dificultando uma escolha prudente do que the seria melhor.

Segundo a OPAS (Organização PanAmericana de Saúde), o novo coronavírus ainda não possui um tratamento comprovado cientificamente e eficaz. O principal foco e investimento a nível mundial neste momento é no desenvolvimento de uma vacina, mas o processo é longo e demorado, pois são realizadas várias fases de testes e mesmo quando uma com resultados satisfatórios e seguros for encontrada, a distribuição para o mundo todo levará algum tempo considerável. Isto posto, os grupos antivacina já começam a influenciar a humanidade a partir de suas escolhas, como a de não ser vacinado, não acreditar na ciência, inventar teorias conspiratórias, entre outros, ou seja, a responsabilidade de um movimento desse nível é muito grande para com toda humanidade, pois engajam muitas pessoas em suas escolhas e prejudicam a veiculação de informações corretas e comprovadas.

Constantemente, a partir do pensamento sartreano, a reflexão é conduzida para a responsabilidade do incessante escolher de si próprio, bem como, para o engajamento pessoal do sujeito com seu projeto original, que segundo o autor, é a escolha que o indivíduo que faz de si, onde a cada instante vê-se na iminência de dar coordenadas para fazer de sua condição, um exemplo de intencionalidade para toda consciência (fenômeno) que se dá, mas de forma que esta, venha a servir de exemplo para toda a humanidade. Sobre o tema, Perdigão (1995) afirma que é importante salientar que a liberdade de escolher não indica que o homem pode agir de qualquer maneira, fazendo o que quer a qualquer momento, pois existe uma coerência interna, uma maneira própria de ser de cada indivíduo. Suas atitudes abrigam um significado mais profundo, refletindo a escolha de si mesmo, que comporta todas as suas ações. De acordo com o autor:

[...] o projeto fundamental é contemporâneo aos atos, existe neles, penetra em nossas escolhas, emoções, tendências etc., enquanto seu fundamento mesmo. Todas as manifestações concretas da vida humana são diferentes expressões desse projeto fundamental. Não houvesse tal projeto, cada homem agiria de modo incoerente e aleatório, o que não sucede nem mesmo com os "dementes" (PERDIGÃO, 1995, p. 105).

Ainda para Perdigão(1995), o projeto original ou projeto fundamental, não é obrigatoriamente fixo, imutável, pois o homem pode mudar as suas escolhas ao longo de sua vida e da construção da sua essência.

Diante desta premissa, a pandemia para alguns pode ter ou não significado uma mudança em seu projeto original diante das incertezas, mudanças de paradigma, adaptações, entre outros.

Consequentemente, tais escolhas e ações necessitam estar isentas, dissociadas da má-fé, precisam ser autênticas, ser reflexo da responsabilidade que é permeada pela liberdade que em um intenso duelo com a angústia de ter que escolher, não escolhe apenas a si mesmo, mas ao outro e a humanidade toda. Sartre afirma que:

Tudo se passa como se a humanidade inteira estivesse de olhos, fixos em cada homem e se regrasse por suas ações. E cada homem deve perguntar a si próprio: sou eu, realmente, aquele que tem o direito 
de agir de tal forma que os meus atos sirvam de norma para toda a humanidade? $E$, se ele não fazer a si mesmo esta pergunta, é porque estará mascarando sua angústia. Não se trata de uma angústia que conduz ao quietismo, à inação. Trata-se de uma angústia simples, que todos aqueles que um dia tiveram responsabilidades conhecem bem. Quando, por exemplo, um chefe militar assume a responsabilidade de uma ofensiva e envia para a morte certo número de homens, ele escolhe fazê-lo, e, no fundo, escolhe sozinho. Certamente, algumas ordens vêm de cima, porém são abertas demais e exigem uma interpretação: é dessa interpretação - responsabilidade sua - que depende a vida de dez, catorze ou vinte homens. Não é possível que não exista certa angústia na decisão tomada. Todos os chefes conhecem essa angústia. Mas isso não os impede de agir, muito pelo contrário: é a própria angústia que constitui a condição de sua ação, pois ela pressupõe que eles encarem a pluralidade dos possíveis e que, ao escolher um caminho, eles se deem conta de que ele não tem nenhum valor a não ser o de ter sido escolhido. Veremos que esse tipo de angústia - a que o existencialismo descreve - se explica também por uma responsabilidade direta para com os outros homens engajados pela escolha. Não se trata de uma cortina entreposta entre nós e a ação, mas parte constitutiva da própria ação (SARTRE, 1970, p. 6).

Diante do afirmado por Sartre, se aplicado ao contexto da pandemia do novo coronavírus, fica claro que cada indivíduo, ao escolher e agir, escolhe e afeta a si mesmo e a toda a humanidade. A responsabilidade da escolha de acatar ou não as orientações e protocolos indicados como prevenção ao contágio, pode implicar diretamente nas escolhas e na vida da humanidade toda, assim como as escolhas e ações da humanidade atuam diretamente no escolher de si próprio. Nesse contexto, o que está em jogo é evidente que é a saúde, a angústia de colocá-la em risco ou preservála e isso, está no projeto original de cada indivíduo de fazer ou não o uso dos EPIs, o distanciamento social e/ou o uso da vacina, quando esta existir.

\section{CONSIDERAÇÕES FINAIS}

\section{O novo coronavírus provocou grandes}

mudanças na vida da população mundial de forma geral. Alterações no comportamento, no cotidiano, nas relações, na saúde, no trabalho, enfim, muitas pessoas precisaram ressignificar suas vidas, ações e escolhas. Nunca a singularidade afetou a universalidade de forma tão significativa como no momento em que convivemos com a presença do coronavírus, até então um desconhecido para todos. A má-fé esteve presente em muitos momentos quando as pessoas tentavam encontrar maneiras de reinventar o cotidiano ou seguir normalmente suas vidas como se não houvesse o risco eminente de contaminação. Alguns governantes negaram as evidências científicas e acabaram por influenciar uma parte da população, assim como as informações desencontradas e contraditórias por parte dos órgãos de saúde puseram em dúvida a veracidade das informações apresentadas a respeito da gravidade da situação.

A partir de um olhar fenomenológico existencial, percebemos como a liberdade vem se dando no contexto da pandemia do coronavírus, visto que a liberdade é uma condição do homem enquanto ser existente. Dessa forma, a existência que é permeada por escolhas e estas compõem a essência de cada indivíduo, é afetada diretamente pela facticidade do surgimento de uma pandemia, assim como pelos significados já dados pelo mundo em que estamos inseridos. Diante deste panorama, as nossas escolhas no dia a dia e principalmente em um período de pandemia tornam-se fundamentais para a nossa liberdade e existência, pois ao escolhermos a nós mesmos, escolhemos o outro também, ou seja, afetamos a escolha do outro e a escolha dele nos afeta.

A angústia pela espera de uma vacina é notável na população mundial, na esperança de que as coisas voltem a uma normalidade e isto pode desconstruir significados e singularidades, pois no momento em que as pessoas viviam a liberdade de suas vidas, tiveram que mudar o foco da sua necessidade, que passou a ser novamente a sobrevivência. Ficou claro nesse período que a nossa liberdade não é absoluta e sim, situada. Portanto, voltar a viver sem a sombra do coronavírus a partir da descoberta de uma vacina não significa viver como vivíamos antes, já que escolhas foram feitas, projetos originais podem ter sido ressignificados e até mesmo a existência de uma vacina eficaz e segura possa demorar um longo tempo para surgir ou nem mesmo chegar a surgir. 
Em virtude deste cenário, a nossa responsabilidade com toda humanidade tornase ainda mais importante, levando em conta que a vida de milhares de pessoas está em risco. Mesmo no contexto do isolamento, do aumento do estresse gerado por isso tudo, das incertezas, dos medos, da insegurança, nossa responsabilidade não deixa de ter menos valor diante da vida das outras pessoas e da nossa própria vida e aí pode residir a esperança de dias melhores. Pois, quando a responsabilidade estiver permeada por respeito ao outro a empatia prevalece, tornando o momento presente mais humano.

\section{REFERÊNCIAS}

BAPTISTA, M.; CAMPOS, D. Metodologias de pesquisa em ciências: Análises Quantitativa e Qualitativa. Rio de Janeiro: LTC, 2007. 299 p.

BARATA, A.; BORIS, G. Angústia e Ansiedade: um esboço histórico-conceitual e uma perspectiva sartreana. In: CASTRO, F.; NORBERTO, S (org.). Sartre hoje, Porto Alegre: Editora Fi, 2017. p.151170.

BEZERRA, A. et al. Fatores associados ao comportamento da população durante o isolamento social na pandemia de COVID-19. Ciênc. saúde coletiva, Rio de Janeiro, v. 25 , supl. 1, p. 24112421, jun. 2020. Disponível em: https://www.scielo. $\mathrm{br} / \mathrm{pdf} / \mathrm{csc} / \mathrm{v} 25 \mathrm{~s} 1 / 1413-8123-\mathrm{csc}-25-\mathrm{s} 1-2411 . \mathrm{pdf}$. Acesso em: 12 out. 2020.

BOCCA, M.; FREITAS, S. Opinião: artigo aborda "liberdade em tempo de pandemia". Portal 24h. Publicado em 12 jun, 2020. Disponível em: https:// www.portal24h.com.br/noticia/5514/opiniao-artigoaborda-liberdade-em-tempo-de-pandemia. Acesso em: 9 ago. 2020.

BOCCA, M. A transcendência vivida em sua temporalidade: Sartre e a experiência psicopatológica. 2019. Tese (Doutorado em Filosofia) - Universidade Estadual do Oeste do Paraná, Campus de Toledo, Toledo, 2019.

CARDOSO, T. Grupos antivacina mudam foco para covid-19 e trazem sérios problemas à saúde pública. Jornal da Universidade de São Paulo. Disponível em: https://jornal.usp.br/?p=311026. Acesso em: 11 out. 2020.
CONASENS - Conselho Nacional de Secretarias Municipais de Saúde; CONASS - Conselho Nacional de Secretários da Saúde. Guia Orientador para o enfrentamento da pandemia Covid-19 na Rede de Atenção à Saúde. Brasília, maio 2020.

COSTA, G. População pobre terá dificuldades em isolamento, afirma infectologista. Agência Brasil. Disponível em: https://agenciabrasil.ebc.com. br/direitos-humanos/noticia/2020-03/populacaopobre-tera-dificuldades-em-isolamento-afirma. Acesso em: 07 dez. 2020.

COX, G. Compreender Sartre. Petrópolis: Vozes, 2007.

ERTHAL, T. Trilogia da existência: teoria e prática da psicologia vivencial. Curitiba: Appris, 2013.

ERTHAL, T. Psicoterapia vivencial: uma abordagem existencial em psicoterapia. Campinas: Livro Pleno, 2004.

FOLHA informativa COVID-19 - Escritório da OPAS e da OMS no Brasil. OPAS Brasil. Disponível em: https://www.paho.org/pt/covid19. Acesso em: 07 dez. 2020.

LEÃO, A. Professor da USP avalia que afrouxar isolamento vai sobrecarregar sistema de saúde. Agência O Globo, 04 jun. 2020. Disponível em: https://oglobo.globo.com/sociedade/coronavirus/ professor-da-usp-avalia-que-afrouxar-isolamentovai-sobrecarregar-sistema-de-saude-24461745. Acesso em: 07 dez. 2020.

MALAVÉ, M. O papel das redes sociais durante a pandemia. Instituto Nacional de Saúde da Mulher, da Criança e do Adolescente Fernandes Figueira (IFF/Fiocruz). Publicado em 18 de maio. de 2020. Disponível em: http://www.iff.fiocruz. br/index.php/8-noticias/675-papel-redes-sociais. Acesso em: 08 nov. 2020.

PERDIGÃO, P. Existência e liberdade, uma introdução à filosofia de Sartre. Porto Alegre: LP\&M, 1995.

PINHEIRO, L. Cada pessoa infectada com Covid-19 transmitiu doença para outras 3 nos primeiros meses da epidemia no Brasil, mostra estudo. G1. 31 jul. 2020. Disponível em: https://g1.globo.com/ 
bemestar/coronavirus/noticia/2020/07/31/cadapessoa-infectada-com-covid-19-transmitiu-doencapara-outras-3-nos-primeiros-meses-da-epidemiano-brasil-mostra-estudo-na-nature.ghtml. Acesso em: 23 ago. 2020.

OMS afirma que COVID-19 é agora caracterizada como pandemia. OPAS Brasil, 11 de mar. de 2020. Disponível em: https:// www. paho.org/bra/index.php? option =com content\&view $=$ article \&id=6120:oms-afirmaque-covid-19-e-agora-caracterizada-comopandemia\&Itemid=812. Acesso em: 08 nov. 2020.

OMS esclarece que assintomáticos transmitem coronavírus: 'a questão é saber quanto'. G1, 09 de jun. de 2020. Disponível em: https://g1.globo. com/bemestar/coronavirus/noticia/2020/06/09/ transmissao-por-casos-assintomaticos-estaocorrendo-a-questao-e-saber-quanto-diz-oms. ghtml. Acesso em: 23 ago. 2020.

REPRESENTANTE da OMS diz que transmissão de Covid-19 por pacientes sem sintomas parece ser rara, mas fala é criticada por pesquisadores. G1, 08 jun. 2020. Disponível em: https://g1.globo. com/bemestar/coronavirus/noticia/2020/06/08/ transmissao-de-covid-19-por-pacientes-semsintomas-parece-ser-rara-diz-oms.ghtml. Acesso em: 23 ago. 2020.

SARTRE, J. P. O existencialismo é um humanismo. Paris: Nagel, 1970.

SARTRE, J. P. O ser e o nada: ensaio de ontologia fenomenológica. 24. ed. Petrópolis: Vozes, 2018.

SOUZA, W. M.de et al. Epidemiological and clinical characteristics of the COVID-19 epidemic in Brazil. Nat Hum Behav. v. 4, p. 856-865, 2020. Disponível em: https://doi.org/10.1038/s41562-020-0928-4. Acesso em: 11 out. de 2020.

\section{LIBERTAD EN EL CONTEXTO DE LA PANDEMIA DEL NUEVO CORONAVIRUS}

RESUMEN: La pandemia de COVID-19 ha provocado distintos cambios de hábitos, costumbres, ocio y en la salud, causando discrepancias de opiniones y sufrimientos psíquicos entre la población. Este artículo tiene por finalidad enfocar desde una visión fenomelógica existencial, la libertad vivida durante la actual pandemia. Buscando promocionar una reflexión a partir de los conceptos fenomenológicos existenciales, como responsabilidad, lógica, proyecto original, entre otros. Relacionando esos con las orientaciones y protocolos sugeridos durante el período pandémico. Delante la importancia de ese tema, y en búsqueda de empoderar la ciencia, es necesario comprender como la libertad ha ocurrido en este periodo y cuáles cuestiones la impregnan. Además, las opciones se han vuelto cada vez más fundamentales para la existencia, impactando directamente en la vida de todos e indicando nuestra responsabilidad para con la humanidad, aunque esté en un momento en que muchas personas están en riesgo debido a un nuevo virus.

PALABRAs ClaVe: Existencialismo; Pandemia; Libertad. 